Ciência e Natura, Santa Maria v.38 n.1, 2016, Jan.- Abr. p. 494 - 512

Revista do Centro de Ciências Naturais e Exatas - UFSM

ISSN impressa: 0100-8307ＩSSN on-line: 2179-460X

\title{
Recursos tecnológicos e temas transversais no ensino da física: um estudo de caso no IFSul/Campus Camaquã
}

\author{
Technological resources and transversal themes in the teaching of physics: \\ a case study at the IFsul/Camaquã Campus
}

\author{
Leandro Neutzling Barbosaํ, Eniz Conceição Oliveira², José Claudio Del Pino ${ }^{3}$ \\ ${ }^{1}$ Instituto Federal de Educação, Ciência e Tecnologia Sul-rio-grandense, Camaquã, RS, Brasil \\ leandro.barbosa@camaqua.ifsul.edu.br \\ ${ }^{2,3}$ Centro Universitário UNIVATES, RS, Brasil \\ eniz@univates.br; jose.pino@univates.br
}

\begin{abstract}
Resumo
Salienta-se que o computador e o software educacional podem ser ferramentas nos processos de ensino e aprendizagem. Diante disso, a presente pesquisa visa analisar as potencialidades dos simuladores computacionais nos processos de ensino e aprendizagem através de uma abordagem transversal sobre o tema "Efeito Estufa". A atividade foi desenvolvida com uma turma de estudantes do $2^{\circ}$ ano do Curso Técnico em Automação Industrial - Forma Integrada, na disciplina de Física II do Instituto Federal de Educação, Ciência e Tecnologia Sulrio-grandense (IFSul)/Campus Camaquã. A proposta adotou por base os pressupostos de uma pesquisa qualitativa com viés exploratório e delineamento metodológico de um estudo de caso. Os resultados foram discutidos a luz da teoria da aprendizagem significativa de Ausubel. É possível destacar que houve uma evolução significativa no conhecimento dos estudantes sobre o tema abordado. Dessa maneira, pode-se concluir que o simulador Physics Education Technology (PhET) tem potencial para auxiliar no processo de ensino e aprendizagem.
\end{abstract}

Palavras-chave: Aprendizagem significativa. Efeito estufa. Simulador phet. Tema transversal. Tecnologias na educação.

Abstract

It stands out that computers and educational software may be tools for the teaching and learning processes. In the face of that, this research aims to analyze the potentials of computer simulators in the teaching and learning processes through a transversal approach on the theme of Glasshouse Effect. The activity was developed with a class of students from the 2 nd year of the Industrial Automation Technical Course - Integrated form, for the subject of Physics II at the Federal Institute for Education, Science and Technology in Rio Grande do Sul IFSul/Camaquã Campus. The proposal adopted as a basis the presumptions of a qualitative research with exploratory bias and methodological outlining of a case study. The results are discussed in the light of Ausubel's significance learning theory. It is possible to highlight that there has been a significant evolution in students' knowledge of the theme covered. Thus, it can be assumed that the Physics Education Technology (PhET) simulator has potential to aid in the teaching and learning process.

Keywords: Significance learning. Glasshouse effect. Phet simulator. Transversal theme. Technologies in education. 


\section{Introdução}

Diante das inovações tecnológicas atuais, um dos grandes desafios da educação é oferecer condições para que as pessoas assumam uma postura autônoma frente às tecnologias do mundo moderno.

Mundo, que acordo com Severiano (2012), nos expõe a uma avalanche de informações que invade nossos sentidos. Estas serão assimiladas conforme o nosso corpo e intelecto julgarem apropriadas para as nossas necessidades, sendo rejeitadas as que julgarem irrelevantes.

E é neste cenário que o professor está inserido. Portanto, é necessário que este se aproprie de tecnologias no seu cotidiano escolar, para que possa ter um comportamento mediador entre o estudante e as tecnologias da informação. Tendo em vista que os recursos tecnológicos são mutáveis, o sujeito é quem determinará o uso que fará desses recursos.

Assim sendo, Demo (2001) enfatiza que a educação deve se valer da sedução, do encantamento e da atração que as tecnologias causam nas pessoas, pois estas são fruto do conhecimento desenvolvido nos próprios espaços educacionais.

Nesse sentido, percebe-se que as Tecnologias da Informação e Comunicação (TIC) podem auxiliar nos processos de ensino e aprendizagem, mas, para isto, torna-se basilar romper com a perspectiva de transmissão de conhecimento, que está fortemente presente na prática docente.

A esse respeito, Brandão e Richetti (2006, p. 63) reiteram sobre a importância de "[...] falar num novo perfil de professor, que exige a preparação para o uso da informática, não apenas no seu aspecto pedagógico, mas, sobretudo, privilegiando sua dimensão pedagógica".

Dessa forma, o professor que estiver consciente de sua função social de sujeito transformador da realidade, reflexivo, capaz de reconhecer na TIC as influências marcantes na relação social e as implicações profundas no modo de vida dos indivíduos poderá potencializar a aprendizagem de seus estudantes.

Esta ideia se apoia nas palavras de Freire (2003, p.77), quando menciona que o professor "deve se assumir como sujeito de transformação no sentido mais radical", ou seja, buscar melhores condições de trabalho, tanto no que tange ao material como espaço físico, salário, desenvolvimento de sua carreira, entre outros, quanto aos aspectos internos relacionados aos compromissos sociais.

Para tanto, cabe ao professor atribuir significado a esta numerosa "parafernália tecnológica" e assim poder contribuir na sua formação profissional e social. Na realidade, não basta que o estudante saiba as funções de todas as teclas e botões, é preciso que exista significação humana e social.

Neste contexto, é válido salientar que o computador e o software educacional são ferramentas nos processos de ensino e aprendizagem. Com isso, uma aula que esteja descontextualizada da realidade do estudante, não atenderá os processos de ensino e aprendizagem de maneira eficaz e, não o fará, mesmo utilizando recursos tecnológicos.

Portanto, não bastam as ferramentas, é necessário saber o que fazer com elas, como as utilizar para melhorar os resultados do processo. Cabe enfatizar que, somente o professor, conseguirá potencializar a aprendizagem com o uso de TIC, no momento em que se sentir incluído digitalmente.

Para isto, necessita não apenas de aparatos tecnológicos, como computadores e softwares, lousas digitais etc., mas, torna-se imprescindível, permitir-se refletir sobre sua prática pedagógica, buscando uma adequada formação permanente, tendo consciência de sua função social.

Assim, sabendo-se da importância de envolver a dimensão social nos processos de ensino e aprendizagem, será abordado neste trabalho o tema sobre o Efeito Estufa. Tal assunto está inserido na sala de aula sob a ótica da transversalidade, conforme recomendam os Parâmetros Curriculares Nacionais - PCN (Brasil, 1998) e, também, preconizado pela Política Nacional de Educação Ambiental (Brasil, 1999).

Ainda, é válido destacar que algumas pesquisas têm procurado investigar as influências das TIC nos processos de ensino e aprendizagem, utilizando simulações computacionais no ensino da Física, salientando a importância do estudo dessa temática (Araujo, 2005; Veit, Teodoro, 2002; Macedo, 2009; Cardoso, 2011; Medeiros; Medeiros, 2002).

Diante do exposto, este trabalho buscará analisar as potencialidades dos simuladores 
computacionais nos processos de ensino e aprendizagem. Propõe-se, para isto, a utilização do simulador computacional Physics Education Technology (PhET) da University of Colorado Boulder, a partir da simulação "Efeito Estufa", disponível para download no endereço eletrônico http://phet.colorado.edu/pt_BR/simulation/greenh ouse.

\section{Contextualização}

Este trabalho foi desenvolvido no Instituto Federal de Educação, Ciência e Tecnologia Sulrio-grandense (IFSul)/Campus Camaquã, situado na Rua Ana Gonçalves da Silva, 901, Bairro Olaria, na cidade de Camaquã, no Rio Grande do Sul/BRASIL. A atividade foi realizada, no mês de agosto de 2013, com a turma de estudantes do $2^{\mathrm{o}}$ ano do Curso Técnico em Automação IndustrialForma Integrada, na disciplina de Física II, composta por 15 estudantes, sendo 11 meninos e quatro meninas, distribuídos na faixa etária entre 15 e 19 anos de idade. Ao trabalhar o tema Termologia, conteúdo curricular previsto no Plano de Ensino da referida turma, abordou-se sobre o Efeito Estufa. Conforme recomendado pelos PCN (BRASIL, 1998), os fenômenos devem ser abordados sob o enfoque de várias disciplinas, possibilitando a sua compreensão ou a solução de um problema concreto sob diferentes ângulos.

Assim, não significa que tais abordagens passem necessariamente pela criação de novas disciplinas. Mas, seguindo o que apontam os PCN (BRASIL, 1998), estas abordagens podem ser realizadas através de temas transversais.

\section{Estrutura metodológica}

Esta proposta tem como base os objetivos de uma pesquisa qualitativa com viés exploratório e delineamento metodológico de um estudo de caso. Optou-se pela pesquisa qualitativa, por entender que não é possível estudar o comportamento de um grupo de pessoas, sem levar em considerações as variáveis interacionistas e interpretativas do próprio pesquisador.

Para Bogdan \& Bliken (1994), na pesquisa qualitativa o investigador tem como fonte direta o ambiente natural, sendo ele o instrumento principal da pesquisa. A coleta de dados, preferencialmente, é feita através de palavras e imagens priorizando o processo e, os dados são analisados de forma indutiva, dando atenção aos significados estabelecidos através do diálogo.

Devido ao tema escolhido possuir muitas variáveis a serem analisadas, optou-se pela pesquisa de cunho exploratória, com viés de um estudo de caso. Conforme Gil (2012, p. 27), as pesquisas exploratórias "tem como principal finalidade desenvolver, esclarecer e modificar conceitos e ideias, com vistas à formulação de problemas mais precisos ou hipóteses pesquisáveis para estudos posteriores".

Para acrescentar, Gil (1995, p. 58) declara que o estudo de caso "não aceita um roteiro rígido para a sua delimitação". Portanto, apresentam-se alguns passos a serem seguidos nesta pesquisa, sendo que tais proposições foram adaptadas a partir de Gil (1995). Dentre os passos: Delimitação da unidade-caso, Coleta de Dados e Análise e interpretação dos dados.

\subsection{Delimitação da unidade-caso}

De acordo com André \& Lüdke (1986), é impossível explorar todos os ângulos do fenômeno investigado, portanto, é imprescindível determinar os focos da investigação e estabelecer seus contornos. Para Gil (2002, p. 138), delimitar a "unidade-caso não constitui tarefa simples, é uma construção intelectual. Não existem limites concretos na definição de qualquer processo ou objeto, os critérios vão variar de acordo com os propósitos da pesquisa".

Neste sentido, Yin ressalta que o estudo de caso como estratégia de investigação é preferido "quando se colocam questões do tipo "como" e "por que", quando o pesquisador tem pouco controle sobre os eventos e quando o foco se encontra em fenômenos contemporâneos inseridos em algum contexto da vida real" (Yin, 2001, p. 19).

Complementando, Yin (2001) considera que o estudo de caso tem caráter empírico, podendo incluir múltiplos estudos de caso ou um único e possuir abordagem tanto quantitativa como qualitativa.

\subsection{Coleta de Dados}

Conforme Gil (2002), o processo de coleta de dados no estudo de caso possui uma 
complexidade maior que o de outras modalidades de pesquisa. Por isso, visando garantir a qualidade das informações, é aconselhável a utilização de mais de um instrumento de coleta. Portanto, apresenta-se a seguinte sequência de atividades adotada:

\subsubsection{Pré-teste}

O pré-teste consistiu em aplicar um questionário impresso que permitisse aos estudantes expressarem suas ideias sobre o Efeito Estufa. O material era composto de oito questões, sendo sete abertas e uma fechada, além disso, foi respondido na primeira aula, tendo como objetivo verificar os conhecimentos prévios dos estudantes sobre o tema.

\subsubsection{Roteiro de atividades}

No segundo encontro, os estudantes utilizaram o laboratório de informática. Para realizar as atividades propostas, foi necessário acessar a simulação "Efeito Estufa" disponível para download no endereço eletrônico http://phet.colorado.edu/pt_BR/simulation/greenhouse, devendo, neste caso, escolher a versão em Português no final da página e clicar na opção "use já".

$\mathrm{O}$ roteiro descrito foi impresso e disponibilizado aos estudantes. Para a realização desta atividade utilizou-se três aulas de 45 minutos.

\subsubsection{Pós-teste}

O pós-teste consistiu em aplicar outro questionário visando verificar a evolução dos estudantes. As perguntas (cinco abertas e uma fechada) integram o roteiro de atividades, sendo que foram respondidas simultaneamente ao momento das ações. As atividades desenvolvidas neste estudo são mostradas sequencialmente no Quadro 1.

Quadro 1- Cronograma do desenvolvimento das atividades

\begin{tabular}{|l|l|l|}
\hline Atividades & Aula $(45 \mathrm{~min})$ & Encontro \\
\hline -Responder ao pré-Teste. & $1^{\underline{\underline{a}}}$ & $1^{\underline{\mathrm{o}}}$ \\
\hline $\begin{array}{l}\text {-Roteiro de atividades/utilização } \\
\text { do simulador PhET; } \\
\text {-Responder ao pós-teste. }\end{array}$ & $2^{\mathrm{a}}, 3^{\mathrm{a}} \mathrm{e} 4^{\mathrm{a}}$ & $2^{\mathrm{o}}$ \\
\hline
\end{tabular}

\section{Discussão dos resultados}

Normalmente, se pressupõe que os resultados de uma pesquisa científica devem, obrigatoriamente, estar de acordo com a hipótese do pesquisador ou apresentar as respostas conforme presumido no problema de pesquisa. Porém, é possível encontrar respostas diferentes ou, por vezes, até resultados que apontem numa direção contrária dos esperados. No entanto, estes fatos, não invalidam a pesquisa.

Tais resultados, obtidos a partir das respostas do pré e pós-teste, foram categorizados e analisados segundo estudos de Moraes (2003) e Galiazzi \& Moraes (2007), sob o enfoque da Análise Textual Discursiva (ATD) e de Bardin (1977), que versa sobre Análise de Conteúdo (AC), além disso, a discussão dos dados foi realizada sob a luz da teoria da Aprendizagem Significativa de Ausubel.

Deste modo, foi feita uma discussão a partir dos elementos que emergiram após a leitura e a categorização dos dados de algumas questões do pré-teste e outras do pós-teste. Os resultados expressados não têm como propósito esgotar a discussão sobre o tema, tampouco, serem considerados como verdades absolutas. Contudo, representam a interpretação distinta destes pesquisadores, podendo servir de referência para futuras pesquisas.

A questão do pré-teste (Você considera os Gases do Efeito Estufa maléficos ou benéficos?) teve por objetivo identificar qual o juízo de valor dos estudantes em relação aos gases do Efeito Estufa. Assim, encontraram-se duas categorias conforme Tabela 1. 
Tabela 1 - Categorias e número de ocorrências da questão do pré-teste Você considera os Gases do Efeito Estufa maléficos ou benéficos?

\begin{tabular}{l|c|c}
\hline Categoria & Subcategoria & Número de ocorrências \\
\hline Maléficos & -- & 11 \\
\hline \multirow{3}{*}{ Benéficos } & $\begin{array}{c}\text { Benéficos independentes da } \\
\text { concentração (BIC) }\end{array}$ & 1 \\
\cline { 2 - 3 } & $\begin{array}{c}\text { Benéficos dependentes da } \\
\text { concentração (BDC) }\end{array}$ & 3 \\
\hline
\end{tabular}

Na categoria denominada, Maléfico, foram relacionadas às respostas que consideraram os gases do Efeito Estufa como maléficos, no qual 11 dos 15 estudantes fizeram tal consideração. Em sua maioria, atribuíram os malefícios ao fator da poluição atmosférica. Duas sentenças que ilustram esta categoria são a do estudante E9, ao afirmar que os gases são "Maléficos, pois esses gases se acumulam na atmosfera poluindo cada vez mais o meio ambiente", e a do estudante E15, ao dizer que são "Maléficos, porque polui o ar que respiramos".

De acordo com a Lei no 6.938 , de 31 de agosto de 1981, que dispõe sobre a Política Nacional do Meio Ambiente, seus fins e mecanismos de formulação e aplicação, além de dar outras providências (Brasil, 1981, texto digital) define poluição como sendo a "degradação da qualidade ambiental resultante direta ou indiretamente" que:

a)prejudiquem a saúde, a segurança e o bem-estar da população;

b)criem condições adversas às atividades sociais e econômicas;

c)afetem desfavoravelmente a biota;

d)afetem as condições estéticas ou sanitárias do meio ambiente;

e)lancem matérias ou energia em desacordo com os padrões ambientais estabelecidos (Brasil, 1981, texto digital).

Já, outras respostas correlacionaram seus malefícios ao aquecimento global, como demonstra a afirmação do estudante E14, ao ressaltar que é "Maléfico, porque provoca o aquecimento global e isso prejudica o planeta" e a do E8: "Maléfico, por contribuírem para o aquecimento global".
Segundo WWF (2014, texto digital) "Aquecimento global é o aumento da temperatura média dos oceanos e da camada de ar próxima à superfície da Terra que pode ser consequência de causas naturais e atividades humanas".

No entanto, outros estudantes mencionaram as influências do $\mathrm{CO}_{2}$, do ozônio e da radiação solar ao justificarem suas posições, como pode ser verificado, respectivamente, pelas respostas do E7, ao declarar que "Os gases são maléficos, pois gases como o $\mathrm{CO}_{2}$ são prejudiciais ao ser humano" e do E5, ao salientar que são "Maléficos, pois se eles destroem a camada de ozônio com o nosso corpo fazem pior" e do E1, ao escrever que são "Maléficos, pois podem dificultar a "saída" da radiação solar que é absorvida pela Terra".

É importante destacar que o $\mathrm{CO}_{2}$, segundo Onça \& Felicio (2011), é um gás natural, existente na atmosfera terrestre, fruto principalmente da decomposição ou da queima de matéria orgânica a partir da reação com o oxigênio. Ainda, conforme os autores, poluição atmosférica e mudança climática são fenômenos distintos, não existindo relação entre o dióxido de carbono e a poluição atmosférica.

Percebe-se, a partir do juízo de valor emitido pelos estudantes sobre os gases do Efeito Estufa, que existe uma dificuldade de distinguir os conceitos de Efeito Estufa, de aquecimento global e destruição da camada de ozônio. Tais evidências também foram apontadas em outros estudos (Libarone; Obara, 2009; Santos; Massabni, 2012).

A categoria denominada, Benéficos, divide-se em duas subcategorias, a saber, Benéficos independentes da concentração (BIC) e Benéficos dependentes da concentração (BDC). Na 
subcategoria BIC enquadrou-se apenas a resposta do estudante E11, que considerou os gases do Efeito Estufa como benéficos, ao dizer que é "Benéfico o $\mathrm{CO}_{2}$, por exemplo, contribui para o efeito estufa, mas é resultado da nossa respiração, sem respiração não há vida e viver é bom".

A subcategoria BDC acolheu as respostas dos estudantes que consideraram os efeitos dos gases do Efeito Estufa tanto maléficos quanto benéficos, como demonstra as sentenças dos estudantes E3, ao dizer que "Acredito que um pouco de cada um, porque ao mesmo tempo em que mantém o planeta aquecido, aquece ele demais" e a do estudante E4, ao afirmar que "Depende do caso, porque existem alguns casos que o fenômeno contribui e, outros casos, é prejudicial". Já, o estudante E6, justificou sua resposta escrevendo que "depende, pois em determinadas quantidades dos gases são benéficos e/ou maléficos. Por exemplo: $\mathrm{CO}_{2}$ em pouca quantidade é fundamental para as plantas, já em grandes quantidades é maléfico para os seres vivos e para o ambiente causado pelo efeito estufa".
Ao analisar as categorias emergentes desta questão, é possível inferir que os estudantes possuem subsunçores relacionados ao tema (Ausubel, 2003). Porém, percebe-se que tais subsunçores não são específicos. Isto pode ocorrer devido ao processo de diferenciação progressiva não estar completo, fazendo com que o estudante não diferencie os subsunçores existentes em sua estrutura cognitiva e, dessa maneira, se utiliza de subsunçores próximos que estejam disponíveis (Ausubel, 2003; Moreira, 2008).

A questão do pós-teste (A partir das observações realizadas, você considera os Gases do Efeito Estufa maléficos ou benéficos? Explique) visou identificar qual o juízo de valor dos estudantes em relação aos gases do Efeito Estufa. A partir da análise desta questão emergiram três categorias, Maléficos, Benéficos e Outras, sendo que a segunda foi dividida em duas subcategorias denominadas de Benéficos independentes da concentração (BIC) e de Benéficos dependentes da concentração (BDC), conforme a Tabela 2.

Tabela 2 - Categorias e número de ocorrências sobre o juízo de valor dos estudantes sobre os gases do Efeito Estufa após a interação com o simulador

\begin{tabular}{l|l|c}
\hline Categoria & Subcategoria & Número de ocorrências \\
\hline Maléficos & -- & 5 \\
\hline \multirow{3}{*}{ Benéficos } & $\begin{array}{l}\text { Benéficos independentes da } \\
\text { concentração (BIC) }\end{array}$ & 1 \\
\cline { 2 - 3 } & $\begin{array}{l}\text { Benéficos dependentes da } \\
\text { concentração (BDC) }\end{array}$ & 8 \\
\hline Outras & -- & 1 \\
\hline
\end{tabular}

Na categoria designada Maléficos, registraram-se as respostas que consideraram os gases do Efeito Estufa como maléficos, pois aumentam a temperatura da Terra. Podem-se citar algumas respostas que expressam tal categoria, como a do estudante E10, ao afirmar que são "Maléficos, pois aumentam a temperatura da Terra", a do E12, que considerou "Maléficos porque eles interferem no retorno dos fótons infravermelhos fazendo a Terra ficar mais quente". Já, o estudante E5 declarou que são "Maléficos, pois o céu não fica tão limpo e aumenta a taxa de fóton solar e fóton infravermelho presentes na Terra".
É provável que os estudantes chegassem a tais conclusões a partir da interação com o simulador. Isso porque, uma das possibilidades deste simulador é representar as alterações na temperatura, na quantidade de fótons solares, na quantidade de fótons infravermelhos e na mudança de tonalidade da atmosfera quando modificamos a concentração de gases do Efeito Estufa.

Desse modo, apresentam-se duas situações de interação com o simulador a título de ilustração, as quais serão denominadas de " $A$ " e " $B$ ". Na situação " $A$ ", utiliza-se a concentração de gases do Efeito Estufa em "Nenhum" (Figura 1) e na 
situação "B" utiliza-se a concentração de gases do Efeito Estufa em "Muitos" (Figura 2).

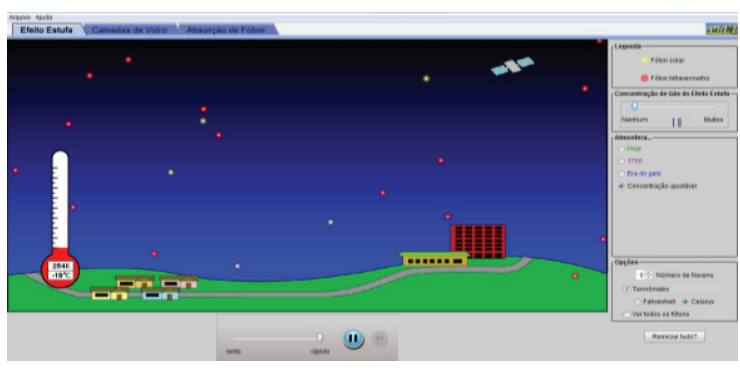

Figura 1 - Imagem do simulador, que demonstra a atmosfera quando selecionado a concentração de gases do Efeito Estufa em "Nenhum"

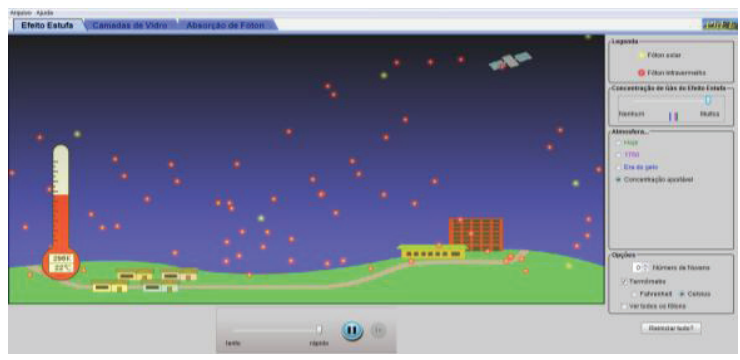

Figura 2 - Imagem do simulador, que demonstra a atmosfera quando selecionado a concentração de gases do Efeito Estufa em "Muitos"

Ao comparar as duas situações, observa-se que a temperatura registrada na situação " $\mathrm{A}$ " é de -19 ${ }^{\circ} \mathrm{C}$, menor que na situação "B", que é de $22^{\circ} \mathrm{C}$. A tonalidade da atmosfera em " $\mathrm{A}$ " é mais clara que em " $B$ ", e que a situação " $B$ " apresenta uma quantidade de fótons infravermelhos maiores que a situação "A". No entanto, em relação à quantidade de fótons de luz não há alteração.

Observa-se, também, que a interação com o simulador possibilitou que os estudantes percebessem algumas influências dos gases de Efeito Estufa, como aumento de temperatura, retenção de fótons infravermelhos e tonalidade da atmosfera terrestre. Porém, o estudante E5 não foi capaz de perceber que os fótons solares não são alterados pela variação da concentração destes gases.

Por outro lado, os estudantes não perceberam, a partir da simulação, que sem a presença dos gases do Efeito Estufa a temperatura na Terra seria muito baixa, o que traria dificuldades para a manutenção da vida.
Diante disso, pode-se inferir que para este grupo de estudantes, o simulador não foi eficaz no sentido de compreenderem os gases do Efeito Estufa como benéficos.

A categoria Outras, abrigou apenas a resposta do estudante E11, pois, destoou das demais ao relatar que "Não sabendo se o fóton infravermelho é benéfico não tenho como responder, levando em conta que são maléficos, então os gases também são, já se são benéficos os gases podem ser", revelando desconhecimento sobre a radiação infravermelha. No entanto, esta resposta pode ser um indicativo de que o estudante conseguiu perceber as alterações nas quantidades de fótons infravermelhos conforme variava a concentração de gases do Efeito Estufa.

$\mathrm{Na}$ categoria Benéficos, registraram-se as respostas dos estudantes que consideraram os gases do Efeito Estufa como benéficos, sendo divididas em duas subcategorias. Na subcategoria BIC enquadrou-se a resposta do estudante E15, ao citar que são "Benéficos porque se não tiver gás do efeito estufa a Terra seria muito fria e com os gases teria uma temperatura boa". Destaca-se que este estudante percebe a influência dos gases do Efeito Estufa, para a manutenção da temperatura terrestre, adequada para a manutenção da vida. Porém, não menciona que o aumento na concentração destes gases pode potencializar o Efeito Estufa, com consequências negativas para a vida.

$\mathrm{Na}$ subcategoria BDC, incluiu-se as respostas dos estudantes que consideraram os gases do Efeito Estufa benéficos, considerando suas concentrações, ou seja, sendo benéficos em concentrações normais (naturais) e maléficos em concentrações elevadas (principalmente, aumentadas pelas ações antrópicas). As sentenças que elucidam esta categoria são as dos estudantes E1, ao dizer que "Considero benéficos, pois mantém a temperatura em condições estáveis para vida no planeta, pois sem eles a Terra seria muito fria. Mas também há o lado maléfico, pois se for muito grande a quantidade desses gases, o calor pode ser retido na Terra, assim aumentará a temperatura média do planeta", a do E14, ao salientar que

Ele pode ser considerado benéfico, porque através da composição entre o "nenhum" e "muito", percebi que se não houvesse o efeito estufa as temperaturas seriam muito baixas e talvez não existiria vida[...]. Mas também pode ser 
maléfico porque em excesso pode aquecer o planeta demais (E14).

$\mathrm{O}$ estudante E7, também ressalta que "Um pouco é necessário, pois sem morreríamos de frio, mas muito também não, pois a temperatura pode subir muito". Já, o estudante E9, deixa implícito que há um lado maléfico, ao afirmar que "Por um lado benéficos, pois sem a presença dos gases do Efeito estufa o planeta ficaria em uma temperatura muito baixa".

Tais resultados, em que os estudantes consideraram os gases do Efeito Estufa como benéficos, fazendo menção que sua presença exacerbada na atmosfera é indesejável, tendo como uma das consequências a elevação da temperatura da Terra, correspondendo com os estudos citados anteriormente.
Ao comparar os resultados das duas questões discutidas, verificou-se que houve alteração no juízo de valores dos estudantes sobre os gases do Efeito Estufa presentes na simulação, conforme demonstra a Figura 3. No pré-teste, 11 dos 15 estudantes consideraram os gases do Efeito Estufa como maléficos e quatro consideram benéficos. Contudo, no pós-teste, 10 dos 15 estudantes consideram benéficos e quatro consideram maléficos. Portanto, observa-se que após a interação com o simulador, ocorreu uma alteração de quatro para 10 estudantes que manifestaram juízo de valor sobre os gases do Efeito Estufa em consonância com a maioria dos estudos sobre este tema.

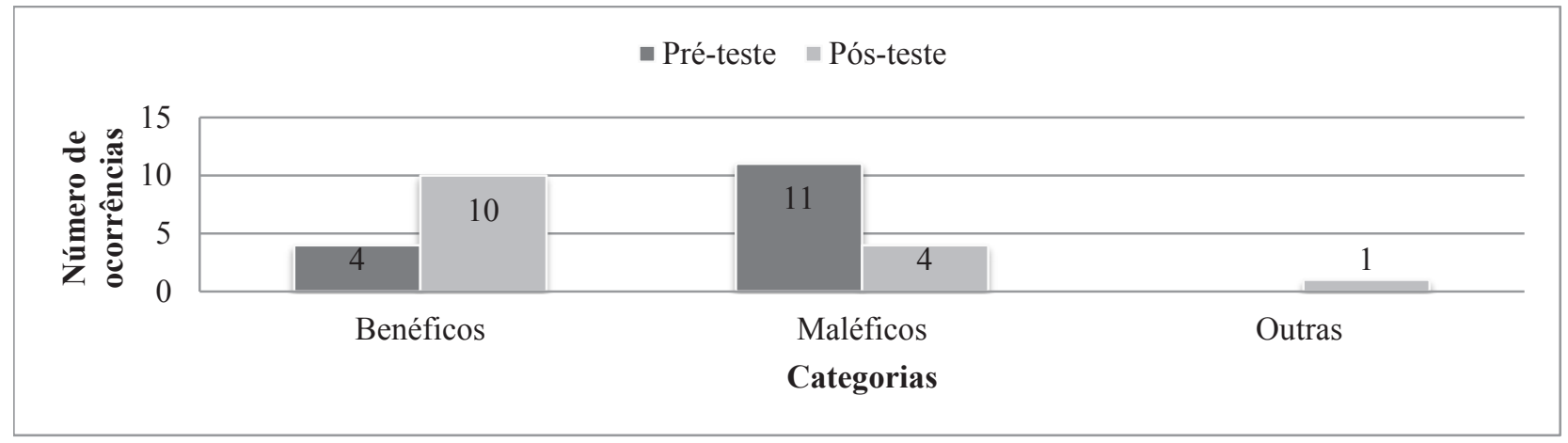

Figura 3 - Gráfico comparativo das respostas do pré-teste e pós-teste referentes à alteração no juízo de valor quanto às influências provocadas no clima pelos gases do Efeito Estufa

A questão do pré-teste (Marque C para os gases atmosféricos terrestres que julgar que contribuem para o Efeito Estufa e marque NC para os gases atmosféricos terrestres que julgar que não contribuem para o Efeito Estufa.), visou identificar qual (is) gás (es) os estudantes consideram contribuir para o Efeito Estufa. Sendo que os gases foram categorizados em contribui e não contribui (Tabela 3).

Tabela 3 - Categorias e número de ocorrências de cada gás que contribui ou não para o Efeito Estufa

\begin{tabular}{l|l|l|l|l|l}
\hline \multirow{2}{*}{ Categorias } & \multicolumn{5}{|c}{ Número de ocorrência de cada gás } \\
\cline { 2 - 6 } & $\mathrm{CH}_{4}$ & $\mathbf{O}_{2}$ & $\mathrm{CO}_{2}$ & $\mathbf{H}_{2} \mathbf{O}$ & $\mathbf{N}_{2}$ \\
\hline Contribui (C) & 13 & 2 & 14 & 1 & 12 \\
\hline Não Contribui (NC) & 2 & 13 & 1 & 14 & 3 \\
\hline
\end{tabular}

Dos 15 estudantes, 12 consideraram o gás nitrogênio $\left(\mathrm{N}_{2}\right)$ presente na atmosfera Terrestre como sendo um dos gases que contribui para o Efeito Estufa. Já, a presença do vapor d'água $\left(\mathrm{H}_{2} \mathrm{O}\right)$ na atmosfera Terrestre foi considerado por
14 estudantes como um "gás" que não contribui para o Efeito Estufa. Este resultado equivocado demonstra que apesar do Efeito Estufa ser um tema frequente nas diversas mídias, ainda, carece de uma abordagem mais aprofundada. 
Conforme Molion (2014) e Panzera \& Moura (2014), os gases que contribuem para o Efeito Estufa são o dióxido de carbono $\left(\mathrm{CO}_{2}\right)$, o vapor d'água $\left(\mathrm{H}_{2} \mathrm{O}\right)$, o ozônio $\left(\mathrm{O}_{3}\right)$, o óxido nitroso $\left(\mathrm{N}_{2} \mathrm{O}\right)$, o metano $\left(\mathrm{CH}_{4}\right)$ e compostos de clorofluorcarbono (CFC).

O gás Nitrogênio $\left(\mathrm{N}_{2}\right)$, de acordo com Panzera \& Moura (2014), é o gás presente em maior quantidade no ar atmosférico, perfazendo $78 \%$. Este gás pouco reage com outros elementos ou substâncias químicas, sendo "fundamental para a vida na Terra, pois faz parte da composição das proteínas, que são moléculas presentes em todos os organismos vivos" (Nitrogênio, 2014).
Já a questão do pré-teste (Coloque em ordem crescente, de acordo com a contribuição para o Efeito Estufa, SOMENTE, os gases presentes na atmosfera que julgaste contribuir para o Efeito Estufa), teve por objetivo verificar a percepção dos estudantes quanto aos efeitos dos gases que consideraram contribuir para o Efeito Estufa, e os resultados foram categorizados em sequências (Tabela 4) e grau de contribuição (Tabela 5).

Tabela 4 - Categorias e número de ocorrências de cada sequência dos gases que foram considerados contribuir para o Efeito Estufa

\begin{tabular}{l|l|c}
\cline { 2 - 3 } \multicolumn{2}{c|}{ Categorias } & Número de ocorrências \\
\hline \multirow{4}{*}{ Sequências } & $\mathrm{CH}_{4}<\mathrm{CO}_{2}$ & 4 \\
\cline { 2 - 3 } & $\mathrm{N}_{2}<\mathrm{CH}_{4}<\mathrm{CO}_{2}$ & 5 \\
\cline { 2 - 3 } & $\mathrm{O}_{2}<\mathrm{CO}_{2}<\mathrm{N}_{2}<\mathrm{CH}_{4}$ & 1 \\
\cline { 2 - 3 } & $\mathrm{CH}_{4}<\mathrm{CO}_{2}<\mathrm{N}_{2}<\mathrm{H}_{2} \mathrm{O}<\mathrm{O}_{2}$ & 1 \\
\cline { 2 - 3 } & $\mathrm{N}_{2}<\mathrm{CO}_{2}$ & 1 \\
\cline { 2 - 3 } & $\mathrm{N}_{2}<\mathrm{O}_{2}<\mathrm{CO}_{2}$ & 1 \\
\cline { 2 - 3 } & $\mathrm{N}_{2}<\mathrm{CO}_{2}<\mathrm{CH}_{4}$ & 1 \\
\cline { 2 - 3 } & $\mathrm{N}_{2}<\mathrm{CH}_{4}$ & 1 \\
\hline
\end{tabular}

Tabela 5 - Categorias e número de ocorrência dos gases classificados conforme grau de contribuição no Efeito Estufa

\begin{tabular}{|c|c|c|c|c|c|}
\hline \multirow{2}{*}{ Categorias } & \multicolumn{5}{|c|}{ Número de ocorrências dos gases } \\
\hline & $\mathrm{CH}_{4}$ & $\mathrm{O}_{2}$ & $\mathrm{CO}_{2}$ & $\mathrm{H}_{2} \mathrm{O}$ & $\mathbf{N}_{2}$ \\
\hline Mais Contribui & 3 & 1 & 11 & -- & -- \\
\hline Menos Contribui & 5 & 1 & -- & -- & 9 \\
\hline
\end{tabular}

Dos 15 estudantes pesquisados, 13 consideram o gás metano $\left(\mathrm{CH}_{4}\right)$ como um gás que contribui para o Efeito Estufa (Tabela 3), sendo que três comentaram que tal gás é o que mais contribuiu e cinco disseram que menos contribuiu para o Efeito Estufa (Tabela 5).

$\mathrm{O} \mathrm{CH}_{4}$ é um hidrocarboneto de cadeia simples, encontrado na atmosfera em uma proporção de $1700 \mu \mathrm{g} \mathrm{L} \mathrm{L}^{-1}$, incolor e inodoro, possui baixa solubilidade em água e ao ser adicionado ao ar, seu potencial explosivo fica alto. Ainda, sua obtenção pode ser feita através da extração de combustíveis do tipo minerais, especialmente, o petróleo; do metabolismo de algumas bactérias; do processo digestivo natural de animais herbívoros; de vulcões de lama; do aquecimento de biomassa anaeróbica e da decomposição do lixo orgânico, sendo assim, considerado um biogás (A Utilização, 2013).

Conforme os dados do Painel Intergovernamental Sobre Mudança do Clima (2007), a concentração de CH4 na atmosfera sofreu um aumento significativo entre a época pré-industrial e o início da década de $90 \mu \mathrm{g}$ L-1, passando de aproximadamente $715 \mu \mathrm{g}$ L-1 para aproximadamente $1732 \mu \mathrm{g} \mathrm{L-1}$, chegando a um valor em torno de $1774 \mu \mathrm{g}$ L-1 em 2005. Neste ano, atingiu valores muito superiores se comparados 
com os últimos 650.000 anos, que eram em torno de 320 a $790 \mu \mathrm{g}$ L-1. Ainda, de acordo com o Intergovernmental Panel on Climate Change IPCC - (2007), desde o início da década de 90, as taxas de aumento da concentração de $\mathrm{CH}_{4}$ mantiveram-se constante, o que permite afirmar que, provavelmente, o aumento verificado a partir da época pré-industrial ao início da década de 90, se deu por atividades antrópicas, podendo-se citar o uso de combustíveis fósseis e as atividades agrícolas. No entanto, outras fontes de contribuição não estão bem definidas.

Por outro lado, Molion (2014) ressalta que as concentrações de $\mathrm{CH}_{4}$ estavam crescendo na ordem de $1,0 \%$ ao ano, sendo que este crescimento estava atribuído às atividades agropecuárias, no entanto, este crescimento diminuiu a partir de 1998, de maneira inexplicável, porém, as emissões de fontes antrópicas continuaram crescendo.

Já, o dióxido de carbono $\left(\mathrm{CO}_{2}\right)$ é apontado por 14 dos 15 estudantes como sendo um dos gases responsáveis pelo Efeito Estufa (Tabela 3). Quanto ao grau de contribuição, foi relacionado 11 vezes como o que mais contribui para o Efeito Estufa, não sendo apontado como o que menos contribuiu (Tabela 5). Contudo, no que se refere ao grau de contribuição, em ordem crescente, é apontado duas vezes antes do $\mathrm{N}_{2}$ e do $\mathrm{CH}_{4}$ e uma vez antes do $\mathrm{H}_{2} \mathrm{O}$ e do $\mathrm{O}_{2}$ (Tabela 4)

De acordo com o relatório do IPCC (2007), a concentração de $\mathrm{CO}_{2}$ na atmosfera terrestre aumentou de $280 \mathrm{mg} \mathrm{L}^{-1}$ para $379 \mathrm{mg} \mathrm{L}^{-1}$ entre o período pré-industrial e o ano de 2005, ficando muito além dos valores dos últimos 650.000 anos (180 a $300 \mathrm{mg} \mathrm{L}^{-1}$ ). Mais preocupante é o crescimento das concentrações de $\mathrm{CO}_{2}$ verificadas entre os anos de 1995 a 2005, em torno 1,9 mg L-1 por ano, superiores a média de $1,4 \mathrm{mg} \mathrm{L}^{-1}$ medida entre 1960 e 2005, o que permite afirmar que o $\mathrm{CO}_{2}$ é o gás de Efeito Estufa de origem antrópico mais importante.

$\mathrm{O}_{2} \mathrm{O}$ foi citado apenas uma vez como sendo um gás que contribui para o Efeito Estufa e 14 vezes como um gás que não contribui (Tabela 3 ). Já a única vez que este gás foi considerado como um gás do Efeito Estufa, foi apontado como tendo uma contribuição maior que o $\mathrm{CH}_{4}, \mathrm{CO}_{2}$ e $\mathrm{N}_{2}$ (Tabela 4).

Segundo os relatos de Molion (2007), Tomás \& Lombardo (2012), Santos (2000) e Vapor (2014), o vapor d'água presente na atmosfera é o principal gás do Efeito Estufa.

Porém, existem argumentos que contrapõem tais ideias, ao explicar que o vapor d'água é o gás do Efeito Estufa mais abundante na atmosfera e com alto poder de interação com a radiação infravermelha, mas, afirma que seus níveis não sofrem variação, até mesmo, quando a temperatura aumenta; e conclui que, na prática, não há interferência antrópica direta nos níveis de vapor d'água (Efeito, 2014).

No entanto, para Dantas et al. (2014) e Souza (2014), as variações de temperatura provocam alterações nas concentrações de vapor d'água na atmosfera, pois com o aumento de temperatura, o processo de evaporação é potencializado.

Dos 15 estudantes pesquisados, apenas dois consideraram que o $\mathrm{O}_{2}$ contribui para o Efeito Estufa (Tabela 3). Em relação ao grau de contribuição deste gás, um deles apontou como sendo o que mais contribui e o outro o que menos contribui (Tabela 5).

Assim sendo, pode-se dizer que $21 \%$ do volume da atmosfera terrestre são ocupados pelo oxigênio, um gás inodoro, incolor, insípido e não tóxico, sendo considerado o elemento mais importante e vital para os seres vivos. Ainda, ao se combinar com outros elementos, formam compostos que constituem cerca de 88,9\% em massa da água e 49,2\% em massa da crosta terrestre. A partir de descargas elétricas e da ação da radiação ultravioleta, ocorre a formação do ozônio, uma forma alotrópica do oxigênio (Oxigênio, 2014).

$\mathrm{O} \mathrm{N} 2$ foi considerado por 12 dos 15 estudantes pesquisados, como sendo um gás do Efeito Estufa (Tabela 3). No entanto, apareceu nove vezes como o gás que menos contribui para o Efeito Estufa (Tabela 5). No que diz respeito ao grau de contribuição em ordem crescente, este gás ficou posicionado uma vez antes do $\mathrm{CH}_{4}$, do $\mathrm{H}_{2} \mathrm{O}$ e do $\mathrm{O}_{2}$ (Tabela 4).

A questão do pós-teste (Quais os gases atmosféricos contribuem para o Efeito Estufa? Explique) buscou-se saber quais gases os estudantes consideram contribuir para o Efeito Estufa, após terem interagido com o simulador. A Tabela 6 apresenta a categorização e o número de ocorrências desta questão. 
Tabela 6 -Categorias e número de ocorrências dos gases que os estudantes consideram contribuir para o Efeito Estufa

\begin{tabular}{c|l|l|l|l|l}
\hline $\begin{array}{c}\text { Gases que foram } \\
\text { mencionados }\end{array}$ & $\mathrm{O}_{2}$ & $\mathrm{CO}_{2}$ & $\mathrm{H}_{2} \mathrm{O}$ & $\mathrm{N}_{2}$ & $\mathrm{CH}_{4}$ \\
\hline Número de ocorrências & 1 & 14 & 14 & 2 & 13 \\
\hline
\end{tabular}

Após tal categorização, compararam-se os dados da Tabela 6 com os da Tabela 3 (Figura 4). Assim, foi possível perceber que houve alteração no entendimento dos estudantes, após a interação com o simulador sobre quais gases contribuem para o Efeito Estufa.

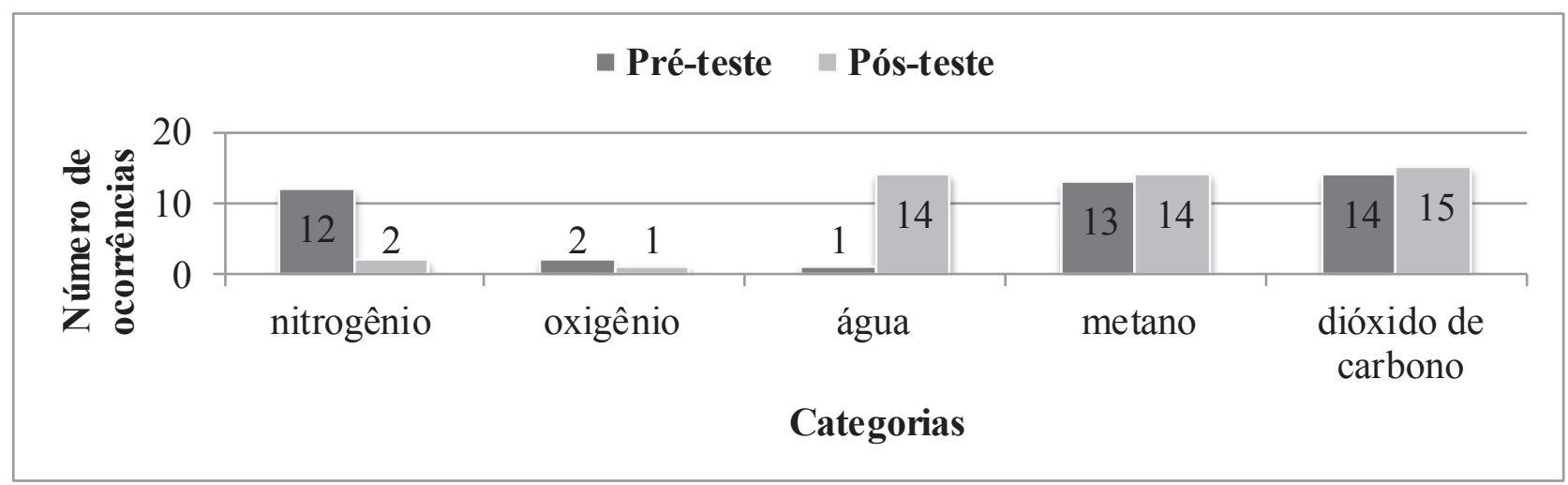

Figura 4 - Gráfico comparativo entre os dados obtidos a partir da categorização das questões do pré e pósteste, que visaram identificar o juízo de valor dos estudantes sobre os gases do Efeito Estufa

É importante destacar que a alteração mais significativa se deu em relação à percepção dos estudantes sobre a participação do vapor d'água e do gás nitrogênio no Efeito Estufa. No pré-teste, apenas um dos 15 estudantes havia considerado a influência do vapor d'água no Efeito Estufa contra 14 no pós-teste. Já com relação ao nitrogênio, 12 dos 15 estudantes no pré-teste haviam considerado a influência desta molécula no Efeito Estufa, passando para somente dois no pós-teste.

Desta forma, é possível inferir que a interação com o simulador auxiliou na identificação de alguns dos gases que provocam o Efeito Estufa e outros que não interferem em tal fenômeno. Essa distinção pôde ser feita, provavelmente, em função de que o simulador possibilita observar a interação ou não da radiação infravermelha com moléculas de gases.
Na simulação, observa-se que há interação da radiação infravermelha com as moléculas dos gases $\mathrm{CO}_{2}$ (Figura 5), $\mathrm{H}_{2} \mathrm{O}$ (Figura 6) e $\mathrm{CH}_{4}$ (Figura 7). Esta interação torna-se visível, pois as moléculas começam a vibrar com a incidência da radiação infravermelha, indicando que estão absorvendo energia, sendo que na sequência emitem fótons infravermelhos.

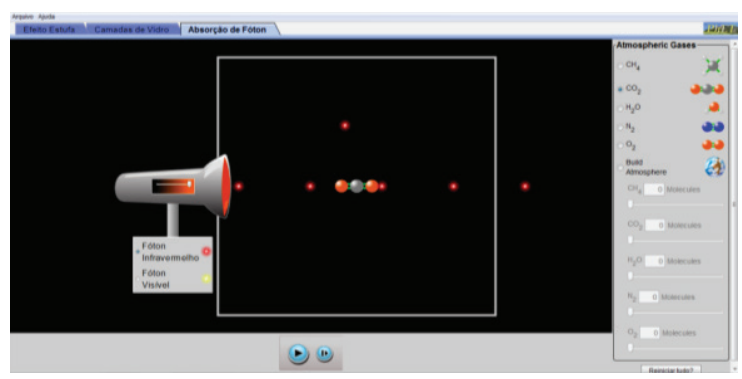

Figura 5 - Incidência de fótons Infravermelhos sobre a molécula de $\mathrm{CO}_{2}$ 


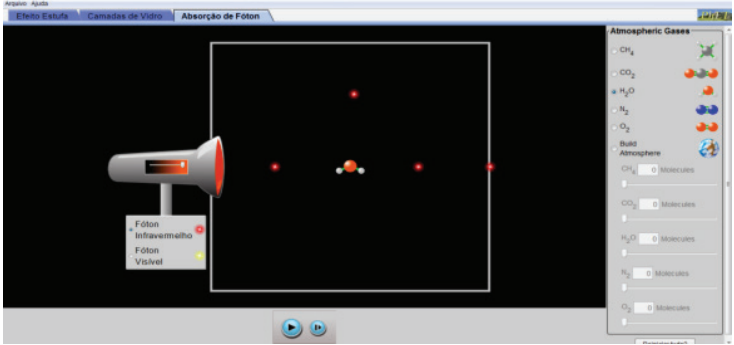

Figura 6 - Incidência de fótons Infravermelhos sobre a molécula de $\mathrm{H}_{2} \mathrm{O}$

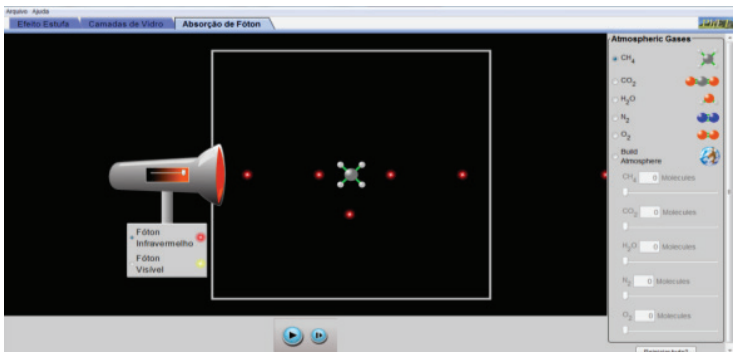

Figura 7 - Incidência de fótons Infravermelhos sobre a molécula de $\mathrm{CH}_{4}$

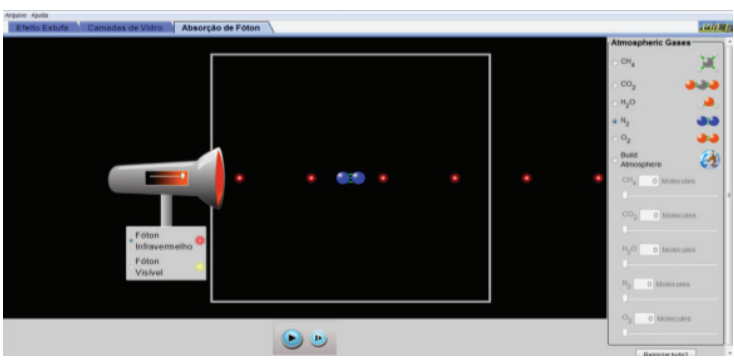

Figura 8 - Incidência de fótons Infravermelhos sobre a molécula de $\mathrm{N}_{2}$

Já nas moléculas de $\mathrm{N}_{2}$ (Figura 8) e $\mathrm{O}_{2}$ (Figura 9) não se observa a vibração e/ou emissão de fótons infravermelhos.
A emissão de fótons infravermelhos pelas moléculas fica visível na simulação, pois são trajetórias variadas. Logo, quando não há interação as trajetórias dos fótons são retilíneas. Ademais, é importante ressaltar que não se observa a vibração das moléculas de $\mathrm{CO}_{2}, \mathrm{H}_{2} \mathrm{O}$, $\mathrm{CH}_{4}, \mathrm{~N}_{2}$ e $\mathrm{O}_{2}$ com a incidência de fótons solares e nem a emissão destes, indicando não haver interação.

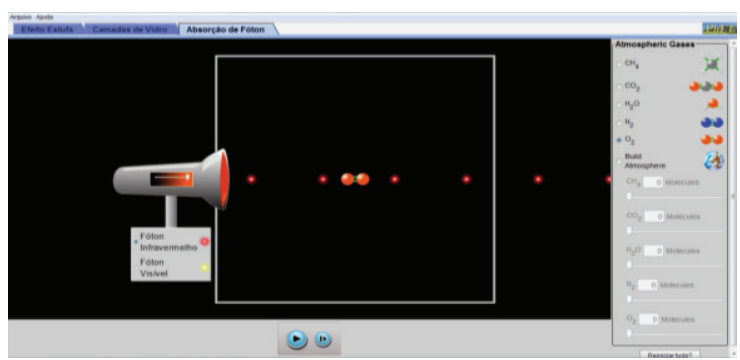

Figura 9 - Incidência de fótons Infravermelhos sobre a molécula de $\mathrm{O}_{2}$

Pode-se dizer que as justificativas apresentadas pelos estudantes para esta questão reforçam, também, o provável auxílio do simulador na identificação dos gases de Efeito Estufa. Algumas sentenças que ilustram esta afirmação são as dos estudantes E15, ao salientar que " $\mathrm{CH}_{4}, \mathrm{CO}_{2}$ e $\mathrm{H}_{2} \mathrm{O}$, porque eles absorvem os fótons infravermelhos e quando liberam a maioria fica concentrada perto do solo" e a do E4, que destaca o " $\mathrm{H}_{2} \mathrm{O}, \mathrm{CO}_{2}$ e $\mathrm{CH}_{4}$ porque quando os fótons de infravermelho são lançados são absorvidos por esses elementos".

A questão do pré-teste (As nuvens interferem no Efeito Estufa?) teve por objetivo verificar a percepção dos estudantes no que se refere à interferência ou não das nuvens no Efeito Estufa. Ao analisar tal questão, emergiram-se três categorias: Interferem, Não Interferem e outras, segundo a Tabela 7 .

Tabela 7 - Categorias e número de ocorrências sobre a interferência ou não das nuvens no Efeito Estufa.

\begin{tabular}{l|c}
\hline Categoria & Número de ocorrências \\
\hline Interferem & 7 \\
\hline Não Interferem & 7 \\
\hline Outras & 1 \\
\hline
\end{tabular}


Na categoria denominada, Interferem (I), sete estudantes consideraram que há influência das nuvens no Efeito Estufa, como pode ser observado nas induções do estudante E4, ao afirmar que "Sim, porque parte do fenômeno pode ser bloqueado por elas". É possível perceber que o este estudante considera que as nuvens formam uma barreira que aprisiona o calor na atmosfera terrestre. Tal percepção fica mais evidente ao analisar a resposta do estudante E12, ao declarar que "Aquelas nuvens que são bem dispersas no ar contribuem, porque elas prendem os raios solares na nossa atmosfera". Salienta-se que outros estudantes também concordam com a ideia de que nuvens formam uma barreira que impede a passagem do calor; porém, estes consideram que tal barreira bloqueia a radiação solar, impedindo que esta entre na atmosfera da Terra, como pode ser verificado nas sentenças dos estudantes E1 ao asseverar que "Sim, pois se não há como os raios saírem consequentemente a Terra ficará mais quente, pois esses raios irradiam calor", do E2, ao dizer que "Penso que as nuvens interferem ao Efeito Estufa, pois quanto maior o número de nuvens menor o número de raios solares que entram na superfície Terrestre" e do E6, ao escrever que "Sim, pois as nuvens são utilizadas como uma barreira que impede a passagem da quantidade de calor irradiado pelo sol".

Conforme Sensoriamento (2014), as nuvens são responsáveis por refletir aproximadamente $20 \%$ da radiação solar e absorver cerca de 3\%. Entretanto, os percentuais de radiação solar que são refletidas pelas nuvens dependem de sua espessura, oscilando entre $40 \%$ e $80 \%$, sendo que, também, as nuvens absorvem e emitem a radiação infravermelha da Terra, auxiliando na manutenção da temperatura durante a noite (Balanço, 2014).

Para o estudante E15, a influência das nuvens no Efeito estufa está relacionada com outro fenômeno, o da chuva ácida, como pode ser verificado a partir da afirmação, "Sim, porque se o ar estiver poluído por gases maléficos quando chover vai ocorrer a chuva ácida matando pouco a pouco a vegetação".
Salienta-se que as chuvas ácidas ocorrem devido à liberação de gases na atmosfera terrestre, como os óxidos de nitrogênio $\left(\mathrm{N}_{2} \mathrm{O}\right.$, $\mathrm{NO}$ e $\mathrm{NO}_{2}$ ) e os de enxofre $\left(\mathrm{SO}_{2}\right.$ e $\left.\mathrm{SO}_{3}\right)$, que ao contrário do $\mathrm{CO}_{2}$, reagem com o vapor d'agua formando ácidos fortes, aumentando a acidez da água da chuva, afetando negativamente plantas e animais e desgastando prédios, monumentos, entre outros (Chuva, 2014).

Por outro lado, um estudo realizado pela Universidade Aberta da Grã-Bretanha, na Escócia, apontou para uma possível desaceleração do Efeito Estufa devido à chuva ácida beneficiar uma espécie de bactéria que compete com a espécie que produz o $\mathrm{CH}_{4}$, provocando sua redução (Chuva, 2004). Outra informação importante, destacada no relatório do Painel Intergovernamental Sobre Mudança do Clima (2007), é que as contribuições antrópicas para os aerossóis provocam um forçamento radiativo $^{1}$ (FR) do albedo ${ }^{2}$ das nuvens de $-0,7$ $\mathrm{Wm}^{-2}$.

Dessa maneira, pode-se inferir que, neste caso, os estudantes não conseguiram fazer generalizações que lhes permitissem perceber semelhanças e diferenças, de forma a integrá-los em uma perspectiva mais abrangente (Moreira, 2008). Pois, a formação das nuvens ocorre devido à condensação do vapor d'água na atmosfera terrestre (Instituto Nacional de Pesquisas Espaciais, 2014). Assim, é provável que, com exceção do estudante E6, todos os demais enquadrados nesta categoria, não consideraram o vapor d'água como um gás do Efeito Estufa.

Além do mais, é possível afirmar que os estudantes possuem subsunçores em suas estruturas cognitivas, em relação à influência das nuvens no Efeito Estufa. No entanto, não correlacionaram corretamente como ocorre tal interferência, indicando que os subsunçores estão mal definidos (Cardoso, 2011).

Quanto à categoria denominada, Não interferem, sete dos 15 estudantes consideraram que as nuvens não influenciam no Efeito Estufa. Sendo que alguns estudantes justificaram a resposta afirmando que as nuvens são formadas por vapor d'água, deixando implícito que devido

\footnotetext{
${ }^{1}$ Forçamento radiativo é uma medida da influência de um fator na alteração do equilíbrio da energia que entra e sai do sistema Terra-atmosfera e é um índice da importância do fator como possível mecanismo de mudança do clima. (Painel Intergovernamental Sobre Mudança Do Clima, 2007).

${ }^{2}$ Albedo é razão entre a quantidade de radiação refletida por um corpo e a quantidade recebida por ele, expressa normalmente em porcentagem (Sensoriamento, 2014).
} 
a essa constituição elas não interferem no Efeito Estufa, o que pode ser verificado na sentença do estudante E5, ao relatar que "Não, pois elas são vapor d'água" e, do estudante E7, ao dizer que "Não, nuvens são água na forma de vapor".

Destaca-se que o estudante E11 também menciona que as nuvens não interferem no Efeito Estufa, porém apenas diz "acredito que não, pois as nuvens não interferem na passagem dos gases e dos raios solares". Já o estudante E8, salienta que "As nuvens não interferem no efeito estufa, pois o efeito é só o aumento da quantidade de gases como o $\mathrm{CO}_{2}$ na atmosfera".

Diante do exposto, é possível concluir que de acordo com os pressupostos de Ausubel (2011), os alunos relacionados nesta categoria, não possuem subsunçores em sua estrutura cognitiva que pudessem os auxiliar na elaboração de um raciocínio, de forma a permitir que eles percebessem as influências das nuvens no Efeito Estufa.

$\mathrm{Na}$ categoria denominada Outras, se enquadrou apenas a resposta do estudante E3, que não se posicionou sobre a influência das nuvens no Efeito Estufa, ao declarar que "Não sei".

A questão do pós-teste (As nuvens interferem no Efeito Estufa? Explique) teve como propósito avaliar se os estudantes conseguiram identificar, após a interação com o simulador computacional, as influências da presença de nuvens no aumento do Efeito Estufa. Ao analisar tal questão, emergiram-se duas categorias: Interferem e Não Interferem, segundo a Tabela 8.

Para integrar a categoria denominada, Interferem, foram consideradas as respostas que conceberam a intervenção das nuvens no Efeito Estufa. A grande maioria dos discentes mencionou que tal interferência ocorre devido à retenção de radiação infravermelha pelas nuvens. Algumas sentenças que demonstram estes argumentos são as dos estudantes E13, ao afirmar que "Sim, porque elas bloqueiam a saída dos fótons infravermelhos", a do E11, ao dizer que "Observando, parece que interferem, pois elas fazem com que os fótons infravermelhos se concentrem mais próximos do solo" e a do E14, ao declarar que "Sim, porque elas absorvem uma pequena parte da radiação".

Destaca-se que uma das possibilidades deste simulador é verificar as influências das nuvens no clima. Sendo assim, é possível observar alterações na temperatura, na quantidade de fótons solares e na quantidade de fótons infravermelhos. Pode-se dizer que ao comparar dois cenários distintos, um com a presença de nuvens, designado de cenário "C" (Figura 10) e o outro sem a presença de nuvens, denominado de cenário "D" (Figura 11), tais alterações ficam mais perceptíveis. No cenário " $\mathrm{C}$ ", é possível verificar que há uma densidade maior de fótons infravermelhos entre a superfície terrestre e as nuvens e uma densidade menor acima das nuvens. No entanto, com relação aos fótons de luz, percebe-se uma densidade maior acima das nuvens e menor abaixo das nuvens.

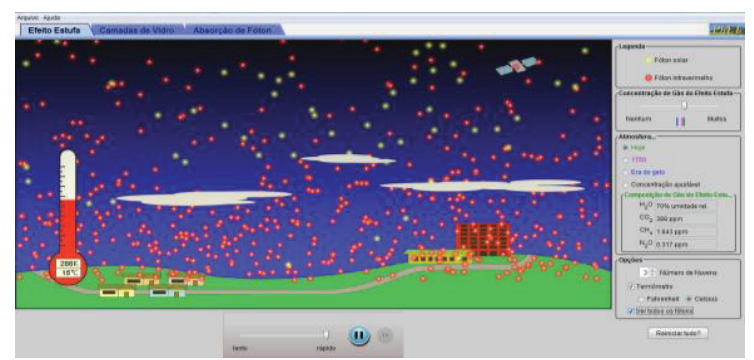

Figura 10 - Cenário "C" com a presença de nuvens

Tabela 8 - Categorias e número de ocorrências da questão dois do pós-teste.

\begin{tabular}{c|c}
\hline Categoria & Número de ocorrências \\
\hline Interferem & 13 \\
\hline Não Interferem & 2 \\
\hline
\end{tabular}

${ }^{1}$ Forçamento radiativo é uma medida da influência de um fator na alteração do equilíbrio da energia que entra e sai do sistema Terra-atmosfera e é um índice da importância do fator como possível mecanismo de mudança do clima. (Painel Intergovernamental Sobre Mudança Do Clima, 2007).

${ }^{2}$ Albedo é razão entre a quantidade de radiação refletida por um corpo e a quantidade recebida por ele, expressa normalmente em porcentagem (Sensoriamento, 2014). 
No tocante do cenário " $\mathrm{D}$ ", observa-se uma concentração de raios infravermelhos com variação gradativa crescente de baixo para cima e concentração gradativa decrescente de fótons de luz de cima para baixo. Com relação à temperatura, observa-se que no cenário “ $\mathrm{D}$ ", o termômetro registra $17^{\circ} \mathrm{C}$, sendo mais elevada que no cenário “ $\mathrm{C}$ ”, no qual registra $15^{\circ} \mathrm{C}$.

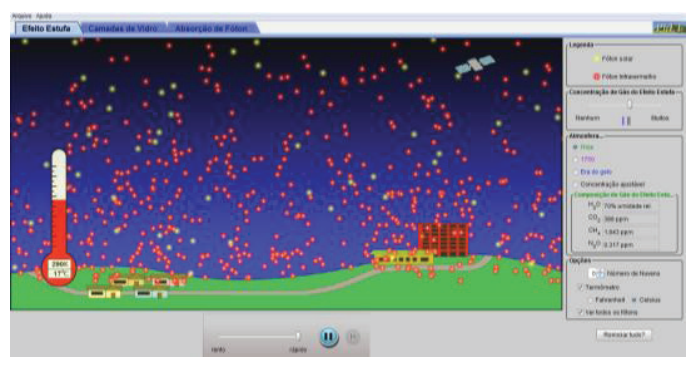

Figura 11 - Cenário “D” sem a presença de nuvens

Assim, conforme as sentenças apresentadas, nota-se que a interação com o simulador foi capaz de demonstrar que as nuvens retém parte da radiação infravermelha. No entanto, o relato do estudante E12 considera "Um pouco, porque tem alguns fótons que ficam presos na atmosfera e também ajuda a refletir algum para o espaço". O estudante E7 afirma que "Sim, elas refletem os fotões infravermelhos, tanto os repelindo como os aprisionando por mais tempo na atmosfera", demonstram que as nuvens absorvem e refletem radiação infravermelha para o espaço. Já, para o estudante E9, houve a possibilidade de observar estudante E9, houve a possibilidade de observar que as nuvens refletem as radiações solares diminuindo o Efeito Estufa, ao declarar que "Sim, elas refletem radiação solar e provocam um efeito contrário aos gases do efeito estufa".

Ainda, destaca-se a resposta do estudante E15, ao mencionar que a influência das nuvens no Efeito Estufa é devido ao aumento da concentração de fótons, que acaba elevando a temperatura. Porém, não cita se são fótons infravermelhos ou fótons de luz, como pode ser verificado na sua afirmação, ao dizer que "Sim, porque com as nuvens aumenta a concentração dos fótons aquecendo muito e causando muito calor".

Quanto à categoria denominada Não interferem, foram enquadradas as respostas dos estudantes que consideraram que as nuvens não contribuem no Efeito Estufa. Como exemplo, tem-se a sentença do estudante E6, que ressalta que "Não, pois a parte da partícula é absorvida sem as nuvens causa a variação de $1^{\circ} \mathrm{C}$ em relação quando há nuvem" e, também, do E4, ao considerar que "Não. Porque mesmo havendo nuvens, as partículas de luz subiam e desciam sem nenhuma alteração em relação aos outros casos". Ressalta-se que apesar de afirmar que as nuvens não interferem no Efeito Estufa, o estudante E6 relata uma variação de um grau Celsius na temperatura.

Após a interação com o simulador, os estudantes alteraram suas concepções sobre a interferência das nuvens no Efeito Estufa.

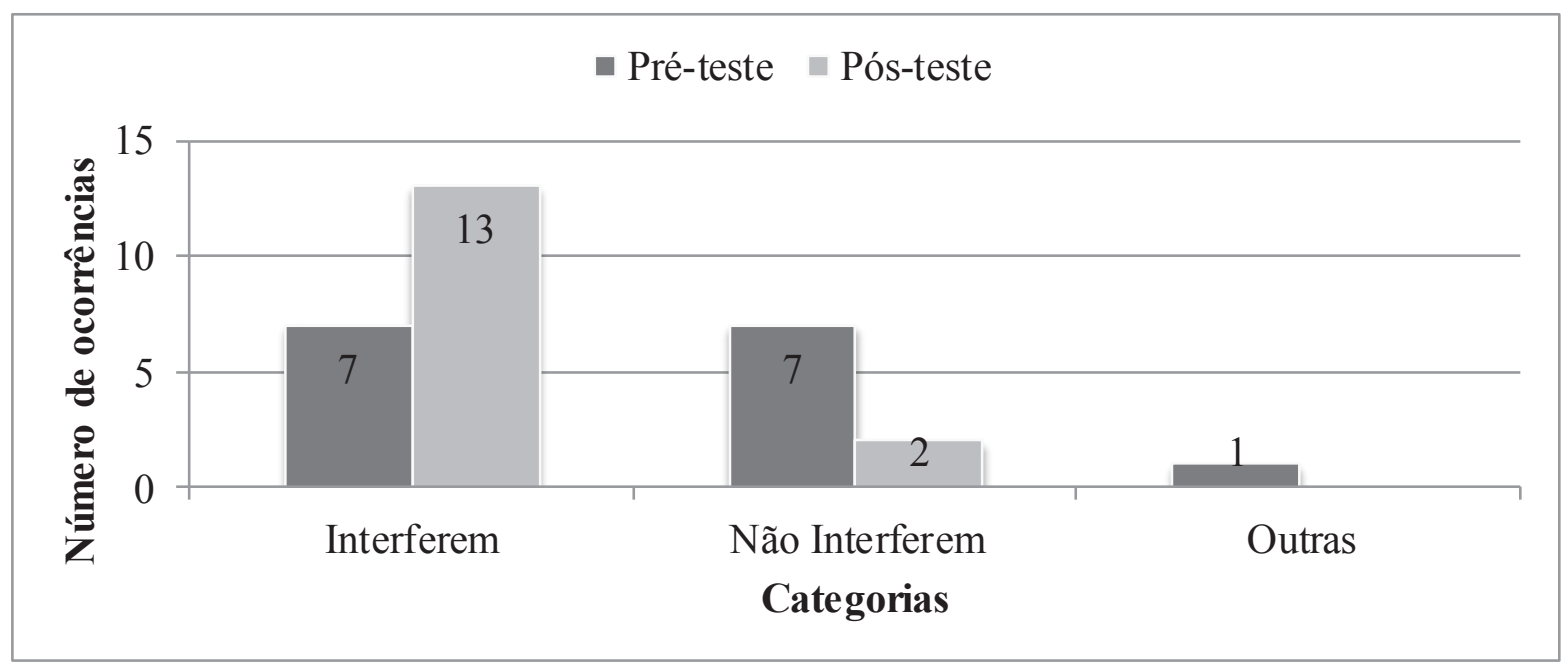

Figura 12 - Gráfico comparativo entre os dados obtidos a partir da categorização das questão 6 do pré e 2 do pós-teste, que visaram identificar o juízo de valor dos estudantes sobre a interferência das nuvens no Efeito Estufa 
Porquanto, ocorreu um acréscimo de respostas que consideraram a interferência das nuvens no Efeito Estufa, passando de sete para 13, acompanhado de uma redução nas respostas que afirmam não haver interferência das nuvens sobre o Efeito Estufa, reduzindo de sete para duas respostas (Figura 12).

\section{Considerações Finais}

As TIC podem auxiliar nos processos de ensino e aprendizagem. Cabe, portanto, encontrar estratégicas didático-metodológicas que auxiliem na construção do conhecimento e, dessa maneira, permitir aos estudantes que assumam posições críticas e reflexivas frente aos temas relevantes que demandam urgência em sua abordagem.

Assim, a escolha deste trabalho "Recursos Tecnológicos e Temas Transversais no Ensino da Física: um estudo de caso no IFSul/Câmpus Camaquã", nasceu de inquietações e percepções provenientes das vivências enquanto professor, remetendo um questionar contínuo sobre a prática docente, afim de encontrar metodologias que possam favorecer os processos de ensino e aprendizagem.

Enfatiza-se que o procedimento metodológico adotado, mostrou-se adequado para que se atingissem os objetivos da proposta. Permitindo, dessa maneira, investigar o uso do simulador PhET como ferramenta capaz de potencializar o processo de ensino e aprendizagem da Física. Com isso, percebeu-se que os estudantes modificaram e ampliaram conceitos sobre o Efeito Estufa. Observou-se, principalmente, que auxiliou na compreensão de que o Efeito Estufa é um fenômeno natural e que as ações antrópicas podem potencializá-lo.

Destaca-se que alguns estudantes, após a interação com o simulador, consideraram os gases do Efeito Estufa como benéficos, no entanto, fizeram menção que sua presença exacerbada na atmosfera é indesejável, tendo como uma das consequências a elevação da temperatura da Terra.

Outra evidência que merece destaque referese à percepção por parte dos discentes sobre os gases que contribuem para o Efeito Estufa. Sendo que a principal alteração se deu sobre a participação do vapor d'agua e do nitrogênio. Uma vez que, antes da interação com o simulador, o vapor d'agua não foi considerado pela maioria dos estudantes como um gás de Efeito Estufa, porém, após a interação com o simulador a maioria dos estudantes considerou este como sendo um gás de Efeito Estufa. Com relação ao nitrogênio, antes da interação com o simulador foi considerado pela maioria dos estudantes como um gás de Efeito Estufa. Porém, após a interação, tal gás não foi considerado um gás de Efeito Estufa.

Ainda, evidenciou-se que após a interação com o simulador, alguns alunos alteraram suas concepções sobre a interferência das nuvens no Efeito Estufa. Porquanto, ocorreu um acréscimo de respostas que consideraram a interferência das nuvens no Efeito Estufa, acompanhado de uma redução nas respostas que afirmam não haver interferência das nuvens sobre o Efeito Estufa.

No entanto, uma ressalva a ser feita sobre o simulador PhET, é que a simulação "Efeito Estufa" não aborda outros gases considerados de Efeito Estufa, como compostos de clorofluorcarbono (CFC).

Por outro lado, salienta-se que a atividade desenvolvida sobre o tema Efeito Estufa, suscitou um momento favorável para a abordagem de temas relacionados à Termologia, à Óptica e à Ondulatória, constituindo-se como tema transversal no ensino da Física.

Finalizando, enfatiza-se que o simulador PhET com relação a simulação "Efeito Estufa" mostrou-se como uma ferramenta capaz de potencializar os processos de ensino e aprendizagem.

\section{Referências}

A Utilização do gás metano.(2013). Disponível em:<http://www.fragmaq.com.br/blog/utilizacao -gas-metano/>. Acesso em: 14 set. 2014.

ANDRÉ, M. E.D.; LÜDKE, M. (1986). Pesquisa em educação: abordagens qualitativas. São Paulo: EPU.

ARAUJO, I. S. (2005). Simulação e modelagem computacionais como recursos auxiliares no ensino de física geral. UFRGS. Disponível em: $<$ http://www.lume.ufrgs.br/handle/10183/5771. Acesso em: 11 ago. 2014. 
AUSUBEL, D. P. (2003). Aquisição e Retenção de Conhecimento: Uma PerspectivaCognitiva.Lisboa: Plátano.

BALANÇO DE RADIAÇÃO (2014). Disponível em:

$<$ http://www.sbmet.org.br/ecomac/pages/trabalh os/balanco\%20de\%20radiacao.txt>. Acesso em: 17 set., 2014.

BARDIN, L. (1977). Análise de conteúdo. Lisboa: Edições 70.

BOGDAN, R.; BIKLEN, S. (1994). Investigação Qualitativa em Educação: uma introdução a teoria e aos métodos. Porto: Porto Editora.

BRANDÃO, E. J. R.; RICHETTI, S. (2006). Informática na educação: a percepção de professores quanto ao uso do computador nas escolas. In: Brandão, E. J. R. (Org). Tecendo Caminhos em Informática na Educação. Passo Fundo:UPF.

BRASIL (1981). Lei n. 6.938, de 31 de agosto de 1981. Política Nacional do Meio Ambiente. Disponível em: $<$ http://www.planalto.gov.br/ccivil_03/leis/16938. htm>. Acesso em: 22 ago. 2014.

BRASIL (1999). Lei n. 9.795, de 27 de abril de 1999. Política Nacional de Educação Ambiental.Disponível em: $<$ http://www.planalto.gov.br/ccivil_03/leis/19795. htm>. Acesso em: 2 set. 2014.

BRASIL (1998). Parâmetros Curriculares Nacionais: terceiro e quarto ciclos, apresentação dos temas transversais. Brasília: MEC/SEF. Disponível em: $<$ http://portal.mec.gov.br/seb/arquivos/pdf/ttrans versais.pdf $>$. Acesso em: 23 de out. 2014.

CARDOSO, S. O. DE O. (2011). Ensinando o efeito fotoelétrico por meio de simulações computacionais: elaboração de roteiro de aula de acordo com teoria da aprendizagem significativa. 116 f. Dissertação (Mestrado em Ensino de Ciência e Matemática) - Pontifícia Universidade Católica, Belo Horizonte, 17 jun. $2011 . \quad$ Disponível em: $<$ http://www.biblioteca.pucminas.br/teses/EnCi Mat_CardosoSO_1.pdf >. Acesso em: 5 dez. 2014.

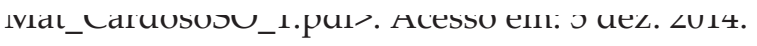

\section{CHUVA ÁCIDA PODE DESACELERAR} EFEITO ESTUFA, diz estudo (2004). Disponível em:

<http://www.bbc.co.uk/portuguese/ciencia/story/ 2004/08/040803_chuvaebc.shtml>. Acesso em: 10 set. 2014.

CHUVA ÁCIDA (2014). Química e Tecnologia da Educação. Disponível em: $<$ http://www.uenf.br/uenf/centros/cct/qambienta 1/ar_chuvacida.html>.Acesso em: 16 set. 2014.

DANTAS, A. A. A. ET AL. O vapor d'água na atmosfera psicrometria. Disponível em: <http://www.deg.ufla.br/site/_adm/upload/file/A grometeorologia/3\%20\%20O\%20VAPOR $\% 20 \mathrm{DA}$ GUA\%20NA\%20ATMOSFERA\%20$\% 20$ PSICROMETRIA.pdf $>$. Acesso em: 15 set. 2014.

DEMO, P. (2001). Conhecimento e aprendizagem na nova mídia. Brasília: Plano.

Efeito estufa (2014). Mudanças climáticas. Disponível em: $<$ http://www.mudancasclimaticas.andi.org.br/no de/661>. Acesso em: 10 set. 2014.

FREIRE, P. (2003). Cartas a Cristina: reflexões sobre minha vida e minha práxis. São Paulo: UNESP.

GALIAZZI, M. DO C.; MORAES, R. (2007). Análise Textual Discursiva. Ijuí: Unijuí.

GIL, A. C. (1995). Como elaborar projetos de pesquisa. São Paulo: Atlas.

Métodos e técnicas de pesquisa social (2012). São Paulo: Atlas.

.Como elaborar projetos de pesquisa (2002). São Paulo: Atlas.

INSTITUTO NACIONAL DE PESQUISAS ESPACIAIS (2014). Princípios de Meteorologia e Meio Ambiente. Centro de previsão de tempo e estudos climáticos. Disponível em: $<$ http://www.cptec.inpe.br/glossario.shtml>.

Acesso em: 16 set. 2014. 
LIBANORE, A. C. L. DA S.; OBARA, A. T. (2009). Concepções alternativas sobre efeito estufa e a formação científica de professores e alunos. In: Encontro Nacional de Pesquisa em Educação em Ciências, Florianópolis. Disponível em:

$<$ http://posgrad.fae.ufmg.br/posgrad/viienpec/pd fs/1628.pdf>. Acesso em: 13 set. 2014

MACEDO, J. A. (2009). Simulações computacionais como ferramenta auxiliar ao ensino de conceitos básicos de eletromagnetismo: elaboração de um roteiro de atividades para professores do ensino médio. 137 f. Dissertação (Mestrado em Ensino de Ciências e Matemática) - Pontifícia Universidade Católica de Minas Gerais, Belo Horizonte, 17 abr. 2009. Disponível em: $<$ http://www.biblioteca.pucminas.br/teses/EnCi Mat_MacedoJA_1.pdf>. Acesso em: 4 nov. 2013.

MEDEIROS, A.; MEDEIROS, C. F. DE (2002). Possibilidades e limitações das simulações computacionais no ensino da física. Revista Brasileira de Ensino de Física, 24 (2), 77-86. Disponível em: $<$ http://www.if.ufrgs.br/cref/ntef/publica.html>. Acesso em: 2 dez. 2013.

Molion, L. C. B. (2014). Desmistificando o Aquecimento Global. Disponível em: $<$ http://www.lgmh.ufpe.br/biomol/AGA/molion_ desmist.pdf $>$. Acesso em: 12 set. 2014.

MORAES, R. (2003). Uma Tempestade de Luz: a compreensão possibilitada pela análise textual discursiva. Ciência \& Educação, 9 (2), 191-211. Disponível em: $<$ http://www.scielo.br/pdf/ciedu/v9n2/04.pdf $>$. Acesso em: 22 jan. 2014.

MOREIRA, M. A. (2008). Aprendizagem Significativa: condições para ocorrência e lacunas que levam a comprometimentos. São Paulo: Vetor.

O NITROGÊNIO (2014). Só biologia. Disponível em:

$<$ http://www.sobiologia.com.br/conteudos/Ar/Ar 1.php>. Acesso em: 11 set. 2014.
ONÇA, D. DE S.; FELICIO, R. A. (2011). Dióxido de Carbono: gás da vida ou poluente atmosférico? Fórum Ambiental da Alta Paulista, 7 (8), 1231-1243. Disponível em: $<$ http://www.amigosdanatureza.org.br/publicaco es/index.php/forum_ambiental/article/view/195/ 194>.Acesso em: 12 set. 2014

OXIGÊNIO (2014). Laboratório Virtual de Química. Disponível em:

<http://www2.fc.unesp.br/lvq/LVQ_tabela/008_o xigenio.html>. Acesso em: 15 set. 2014.

PAINEL INTERGOVERNAMENTAL SOBRE MUDANÇA DO CLIMA (2007). Mudanças do clima 2007:a base das Ciências Físicas.

PANZERA, A. C.; MOURA, D. G. O. Efeito estufa e o clima na Terra. Disponível em: $<$ http://crv.educacao.mg.gov.br/sistema_crv/banc o_objetos_crv/Efeito_Estufa_e_o_clima_na_terra. pdf $>$. Acesso em: 11 set. 2014.

PHET (2013). University of Colorado at Boulder.Interactive Simulations. Disponível em: $<$ http://phet.colorado.edu/pt_BR/simulation/gree nhouse >. Acesso em: 10 abr. 2013.

SANTOS, M. A. DOS (2000). Inventário de emissões de gases de efeito estufa derivadas de hidrelétricas. 147 f. Tese (Doutorado em Ciências em Planejamento Energético) - Universidade Federal do Rio de Janeiro, Rio de Janeiro, RJ, mar. 2000. Disponível em: $<$ http://www.ppe.ufrj.br/ppe/production/tesis/m asantos.pdf $>$. Acesso em: 15 set. 2014.

SANTOS, R. H. M.; MASSABNI, V. G. (2012). Concepções de estudantes de 7 a 9 anos sobre efeito estufa e escassez de água e sua percepção sobre o futuro do mundo. Ensino, Saúde e Ambiente,5 (3), 1-17. Disponível em: $<$ http://ensinosaudeambiente.uff.br/index.php/en sinosaudeambiente/article/view/11/11>.Acesso em: 13 set. 2014.

SENSORIAMENTO REMOTO E RADIAÇÃO ATMOSFÉRICA (2014). Disponível em: $<$ http://www.iag.usp.br/siae98/meteorologia/radi acao.htm>. Acesso em: 16 set. 2014. 
SEVERIANO, L. A. N. (2012). Serviço de Informação à Comunidade: a Biblioteca Pública como instrumento de cidadania e ação social. CRB-8 Digital, 5 (2), 63-68. Disponível em: $<$ http://www.revista.crb8.org.br/index.php/crb8d igital/article/viewFile/95/95>. Acesso em: 11 nov. 2013.

SOUZA, N. J. (2014). Influência das queimadas da Amazônia sobre o efeito estufa.Disponível em:

$<$ http://www.floresta.ufpr.br/alias/lpf/public_ht ml/efeitoestufa.html>. Acesso em: 15 set. 2014.

TOMÁS, D. D.; LOMBARDO, M. A. (2012). Concentração de vapor d'água na atmosfera de áreas urbanas, São Paulo/Brasil. Revista Mercador, 11 (25), 153-167.

VAPOR DE ÁGUA ACELERA AQUECIMENTO GLOBAL (2014). Diário de Notícias. Disponível em:

http://www.dn.pt/inicio/interior.aspx?content_id $=1135850 \&$ page $=-1>$. Acesso em: 15 set. 2014 .

VEIT, E.A.; TEODORO, V. D. (2002). Modelagem no Ensino/Aprendizagem de Física e os Novos Parâmetros Curriculares Nacionais para o Ensino Médio. Revista Brasileira de Ensino de Física, 24 (2), 87-96. Disponível em: $<$ http://www.sbfisica.org.br/rbef/pdf/v24_87.pdf> . Acesso em: 11 set. 2014.

WWF (2014). As Mudanças Climáticas. Disponível em: $<$ http://www.wwf.org.br/natureza_brasileira/red ucao_de_impactos2/clima/mudancas_climaticas2 />. Acesso em: 10 set. 2014.

YIN, ROBERT K (2001). Estudo de Caso: planejamento e métodos. Porto Alegre: Bookman. 